\title{
Controllable Synthesis of ZnO Nanorod-nanosheets Hierarchical Nanostructure on a Stainless Steel Mesh Via A Facile Hydrothermal Growth
}

\author{
Shibu ZHU ${ }^{1,}$ a , Jingpeng ZHAO ${ }^{1}$, Xiaohu ZHANG ${ }^{1}$, Hong CUI ${ }^{1}$ and Zuowan ZHOU ${ }^{2}$ \\ ${ }^{1}$ Xi'an Aerospace Composites Research Institute, Xi'an, 710025, P R China \\ ${ }^{2}$ Key Laboratory of Advanced Technologies of Materials (Ministry of Education), School of Materials \\ Science and Engineering, Southwest Jiaotong University, Chengdu, 610031, P R China \\ a19860917zsb@163.com
}

\begin{abstract}
ZnO}$ nanorods-nanosheets (NR-NS) hierarchical nanostructure consisted of long nanorod and thin nanosheet branches have been built on a stainless steel mesh via a two-step hydrothermal growth process. The related structures and morphologies of the as-prepared products were characterized by X-ray diffraction (XRD) and field emission scanning electron microscopy (FE-SEM). The XRD results confirmed that the obtained samples were wurtzite hexagonal structured $\mathrm{ZnO}$. The FE-SEM observations showed that the smooth surfaces of nanorods were covered by nanosheets, resulting in the enhancement of internal surface area. It was found that trisodium citrate played a crucial role in the formation of $\mathrm{ZnO}$ NR-NS hierarchical nanostructures, and accordingly, the rational growth mechanism was suggested.
\end{abstract}

Keywords: Stainless steel mesh; ZnO NR-NS hierarchical nanostructure; Hydrothermal method; Trisodium citrate

\section{Introduction}

To date, due to the increasing demand for energy and consumption of fossil fuels, finding new energy sources has steadily grown. Solar energy is considered as one of most promising candidates of all alternative energy. Much attention has been paid to dye-sensitized solar cells (DSSCs) owing to their low cost, simplified manufacturing process and possible of large-scale production for next generation solar cells ${ }^{[1,2]}$. Recently, $\mathrm{ZnO}$ with one dimensional (1-D) structures, such as nanowires ${ }^{[3]}$, nanograss ${ }^{[4]}$ and nanotubes ${ }^{[5]}$, have been built for improving conversion efficiency of DSSCs because of their superior electron mobility. However, this kind of DSSCs is commonly based on a rigid FTO or ITO glass substrate, which restricts its adaptability during transportation, installation and flexible application. Flexible DSSCs is a new research field displaying potential application in powering mobile electronic products. Until now, two main kinds of flexible substrates are used for DSSCs, transparent polymer substrates and metal sheets ${ }^{[6,7]}$. Compared to plastic 
and polymer substrates, metal sheet can withstand a high-temperature sintering process and possesses high crystallization of the semiconductor. Recently, stainless steel mesh substrate received much attention ${ }^{[8]}$. The challenge in fabricating stainless steel mesh based flexible DSSCs lies in the successful construction of a well-defined semiconductor oxide on round-like wires to achieve desirable performances. So, it is well worth developing a facile approach to construct nanostructure on stainless steel mesh.

On the other hand, wastewater emissions from the textile industry contain large amounts of dyes, which are considered a major threat to the adjacent ecosystem due to their non-biodegradability, toxicity, and potential carcinogenicity ${ }^{\left[{ }^{[9}\right.}$. Dye removal by photoinduced decomposition of pollutants on photocatalysts has been widely researched ${ }^{[10]}$. $\mathrm{ZnO}$ is also considered as an effective photocatalyst for degrading contaminants [11]. However, most photocatalysts that were studied previously were mobile-type, and only a few immobilized photocatalysts have been reported although they have notable advantages over mobile-type catalysts from a practical perspective. Meanwhile, immobilized photocatalysts showed poor performance due to their closed surface, leading to inefficient mass transference. Thus, $\mathrm{ZnO}$ hierarchical nanostructures built on the stainless steel mesh substrate might present an extensive surface area for photocatalysis.

Herein, we demonstrated a facile two-step hydrothermal procedure of constructing $\mathrm{ZnO}$ nanorods-nanosheets (NR-NS) hierarchical nanostructures on a stainless steel mesh substrate. 1-D $\mathrm{ZnO}$ nanorods perpendicular to the cylindrical metal micro-wires were synthesized and served as a backbone for the second hydrothermal growth of $\mathrm{ZnO}$ nanosheets. The stainless steel mesh supported ZnO NR-NS hierarchical nanostructure possessed large surface area, and it was expected to use as a photoanode for DSSCs or immobilized photocatalysts with the enhancement of related performance.

\section{Experiment}

\subsection{Synthesis of $\mathrm{ZnO}$ nanorod-nanosheet hierarchical nanostructure}

Zinc nitrate hydrate $\left(\mathrm{Zn}\left(\mathrm{NO}_{3}\right)_{2} \cdot 6 \mathrm{H}_{2} \mathrm{O}, 99 \%\right.$, Aladdin $)$, zinc acetate $\left(\mathrm{Zn}\left(\mathrm{CH}_{3} \mathrm{COO}\right)_{2} \cdot 2 \mathrm{H}_{2} \mathrm{O}\right.$, 99\%, Aladdin), hexamethylenetetramine (HMTA, 99\%, Aladdin), trisodium citrate $\left(\mathrm{C}_{6} \mathrm{H}_{5} \mathrm{Na}_{3} \cdot 2 \mathrm{H}_{2} \mathrm{O}\right.$, AR, Aladdin) and polyethylenimine (PEI, $\mathrm{M}_{\mathrm{w}}=800$, Sigma-Aldrich ) were used as received without further purification. The stainless steel mesh (Jinhongyuan Metal Mesh Co., China) was cleaned ultrasonically in acetone, ethanol and distilled water for 15 min, respectively. The growth procedure of the ZnO NR-NS hierarchical nanostructures on a stainless steel mesh is schematically illustrated in Figure 1. The first hydrothermal growth of $\mathrm{ZnO}$ nanorods was as similar as our previous work ${ }^{[12]}$. In a typical process, a $\mathrm{ZnO}$-seeded stainless steel mesh substrate was vertically immersed into the solution containing $25 \mathrm{mM}$ $\mathrm{Zn}\left(\mathrm{NO}_{3}\right)_{2}, 25 \mathrm{mM}$ HMTA, and $7 \mathrm{mM}$ PEI, and the hydrothermal reaction was carried out in a sealed vessel at $92^{\circ} \mathrm{C}$ for $20 \mathrm{~h}$. The growth solutions were refreshed every $4 \mathrm{~h}$ during the reaction period. For the subsequent growth procedure of $\mathrm{ZnO}$ hierarchical nanostructure, the stainless steel mesh substrate coated with $\mathrm{ZnO}$ nanorods was transferred into a vessel containing $10 \mathrm{mM} \mathrm{Zn}\left(\mathrm{NO}_{3}\right)_{2}, 10 \mathrm{mM}$ HMTA and $1 \mathrm{mM} \mathrm{C}_{6} \mathrm{H}_{5} \mathrm{Na}_{3}$ aqueous solution, and the reaction was carried out at $70^{\circ} \mathrm{C}$ for $5 \mathrm{~h}$, resulting in $\mathrm{ZnO}$ NR-NS hierarchical nanostructure. Then, the obtained samples were rinsed with absolute ethanol and distilled water, respectively, and finally dried in air for next characterization. 

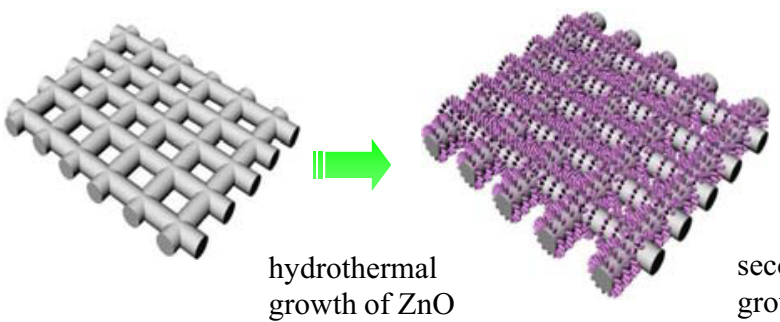

second hydrothermal growth of $\mathrm{ZnO}$

growth of $\mathrm{ZnO}$ NR-NS

Figure 1 Schematic growth procedure of the ZnO NrR-NS hierarchical nanostructure on a

stainless steel mesh

\subsection{Characterization}

X-ray diffraction measurements were performed through a Philips X'Pert PRO X-ray diffractometer (XRD, The Netherlands) with a $\mathrm{CuK}_{\alpha}$ radiation to verify the phase and crystal structure of the $\mathrm{ZnO}$ films. The morphologies of $\mathrm{ZnO}$ nanorods and $\mathrm{ZnO}$ NR-NS hierarchical nanostructure films were characterized by field emission scanning electron microscope (FE-SEM, JSM-7001F, JEOL).

\section{Results and Discussion}

The ZnO NR-NS hierarchical nanostructure on the stainless steel mesh was synthesized by means of a two-step hydrothermal growth. Firstly, $\mathrm{ZnO}$ nanorods array was prepared on a stainless steel mesh by hydrothermal process. Secondly, the second-step hydrothermal reaction of $\mathrm{ZnO}$ nanorods was carried out in the solution containing $\mathrm{Zn}\left(\mathrm{NO}_{3}\right)_{2}$, HMTA and $\mathrm{C}_{6} \mathrm{H}_{5} \mathrm{Na}_{3} \cdot 2 \mathrm{H}_{2} \mathrm{O}$, resulting in the formation of $\mathrm{ZnO}$ NR-NS hierarchical nanostructure. The crystal structures of the stainless steel mesh substrate and as-synthesized samples were characterized by X-ray diffraction (XRD), as shown in Figure 2. The as-prepared sample after the hydrothermal reaction can be indexed as the hexagonal wurtzite-phase, corresponding to (100), (002), (101), (102), (110), (103) and (112) planes of ZnO (JCPDS Card No. 00-036-1451). At the same time, it is obvious that the diffraction peaks at $2 \theta=43.47^{\circ}, 50.67^{\circ}$ and $74.68^{\circ}$ are well assigned to $(111),(200)$ and $(220)$ planes of stainless steel mesh substrate, according to the JCPDS Card No. 00-023-0298, as marked in Figure 2c, respectively. No characteristic peaks arising from reactants or intermediate products are detected, implying the high purity of the prepared $\mathrm{ZnO}$ nanostructure. The diffraction peak intensity corresponded to the $\mathrm{ZnO}$ (002) plane, centered at about $34.34^{\circ}$, surpasses others of $\mathrm{ZnO}$ diffraction peaks, indicating that a high degree of orientation along [001] direction that was perpendicular to the stainless steel mesh substrates. 


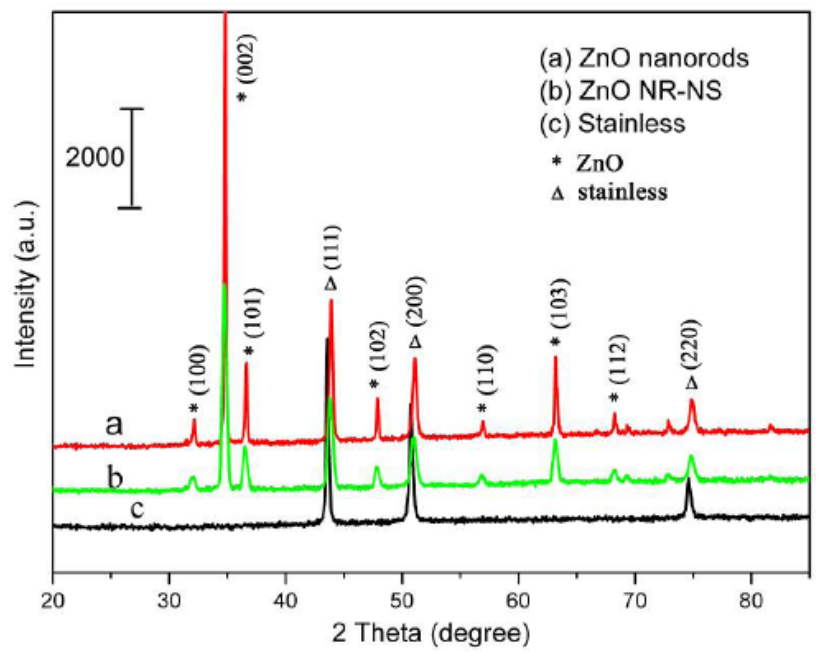

Figure 2 XRD profiles of a stainless steel mesh substrate and as-obtained sample by

\section{hydrothermal growth}

The microstructure of stainless steel mesh substrate was characterized by field emission scanning electron microscope (FE-SEM). Figure $3 \mathrm{a}$ and $\mathrm{b}$ show the top and cross-section views SEM images of a stainless steel mesh substrate. It clearly showed that the substrate was made of the metal round wires with a diameter of about $30 \mu \mathrm{m}$ and quite a smooth surface. The area of the pores was $c a .35 \times 35 \mu \mathrm{m}^{2}$. The porous structures of the stainless steel mesh were in favor of $\mathrm{ZnO}$ growth along with radical direction of a metal wire. Thus, after a $\mathrm{ZnO}$ seed layer prepared on the stainless steel mesh by dip-coating and pyrolysis, $\mathrm{ZnO}$ nanostructure could be webbed with round-shaped wires.

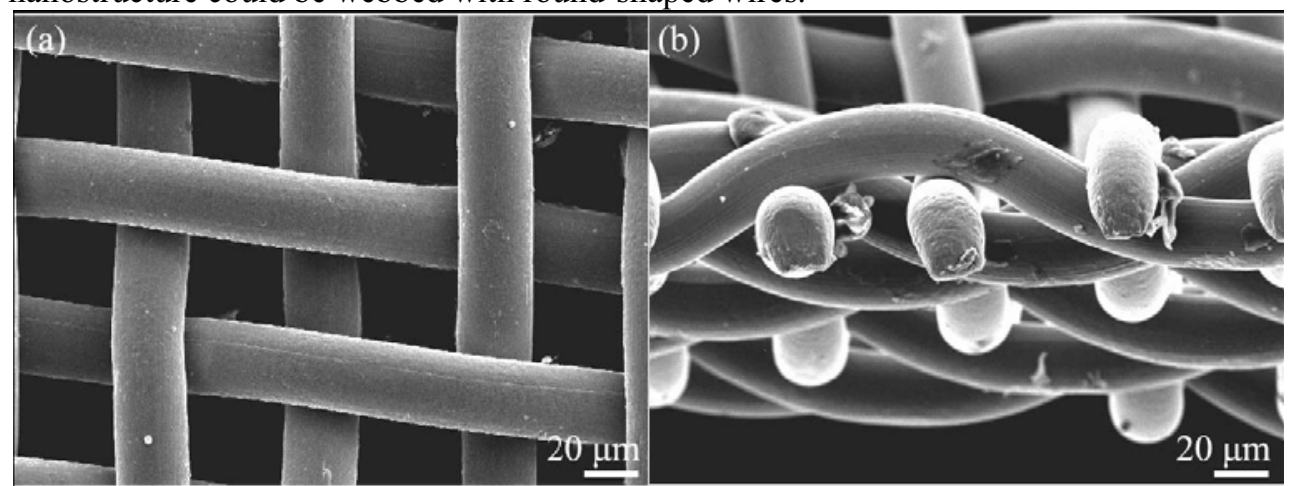

Figure 3 Top view (a) and cross-section (b) SEM images of stainless steel substrate

The color of the stainless steel mesh became white instead of metal luster after the hydrothermal growth, indicating a successful coating with $\mathrm{ZnO}$ nanostructure. The microstructure of obtained samples was displayed in Figure 4. It was found that the diameter of round-like wire increased to $38 \mu \mathrm{m}$, indicating that $\mathrm{ZnO}$ nanorod arrays was uniformly fabricated on the mesh substrate, which was webbed with round-shaped wires (Figure 4a). It was speculated that the length of $\mathrm{ZnO}$ nanorods was $4 \mu \mathrm{m}$. The high-magnification scanning electron microscope image conformed that $\mathrm{ZnO}$ nanorods formed a dense vertically-aligned array in which the diameter of a single nanorod was about 100-150 nm (Figure 4b). Further hydrothermal reaction of $\mathrm{ZnO}$ nanorods/stainless steel mesh in the solution containing 
$\mathrm{Zn}\left(\mathrm{NO}_{3}\right)_{2}$, HMTA and $\mathrm{C}_{6} \mathrm{H}_{5} \mathrm{Na}_{3} \cdot 2 \mathrm{H}_{2} \mathrm{O}$ led to formation of $\mathrm{ZnO}$ NR-NS hierarchical nanostructure consisted of long nanorod backbone and thin nanosheets, as shown in Figure $4 \mathrm{c}$ and $\mathrm{d}$. The length of $\mathrm{ZnO}$ NR-NS hierarchical nanostructure was also about $4 \mu \mathrm{m}$. However, it was clear that the smooth surfaces of $\mathrm{ZnO}$ nanorods were surrounded by the thin nanosheets, forming the rough "shell" out of the $\mathrm{ZnO}$ nanorods, and the average diameter of the ZnO NR-NS hierarchical nanostructure was significantly increased. It had been proven that the smooth surfaces of nanorods covered by nanosheets could result in the enhancement of internal surface area ${ }^{[13,14]}$. The flexible ZnO NR-NS hierarchical nanostructures film might be applied to solar cells and photocatalytic areas.
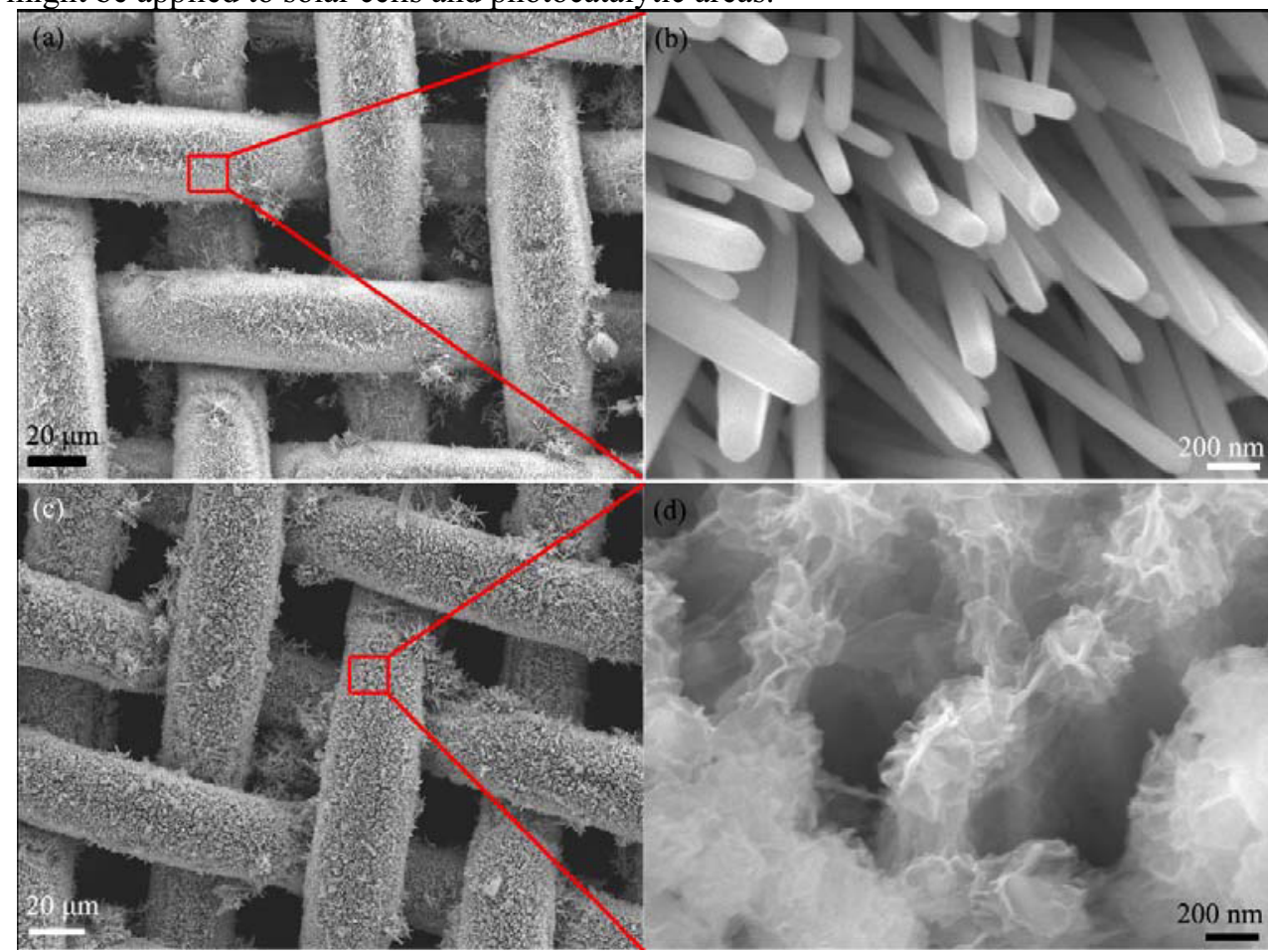

Figure 4 Top-view SEM images of $\mathrm{ZnO}$ nanorods $(\mathrm{a}, \mathrm{b})$ and $\mathrm{ZnO}$ NR-NS hierarchical nanostructure $(c, d)$ on a stainless steel mesh substrate

The ZnO NR-NS hierarchical nanostructure was formed during the second hydrothermal reaction. Compared to the first hydrothermal growth, trisodium citrate was taken place of PEI in the reaction aqueous solution. So, trisodium citrate played an important role in the formation of the nanosheet on the surface of the $\mathrm{ZnO}$ nanorods. As well known, rod-like $\mathrm{ZnO}$ would be received if no citrate anion was added in the reaction solution, due to the higher surface energy of (001) plane and resulting in a faster growth rate along [001] direction ${ }^{[15]}$. However, in the presence of citrate anion, the citrate ion can adsorb onto the positive charged $\mathrm{Zn}^{2+}$ terminated (001) polar plane due to the Coulombic force ${ }^{[16]}$. The absorption effectively slowed down the crystal growth along the [001] direction. At the early growth phase of the second hydrothermal reaction, lots of $\mathrm{ZnO}$ nanoparticles were formed on the surface of $\mathrm{ZnO}$ nanorods. As the reaction continued, $\mathrm{ZnO}$ nanoparticles underwent oriented attachment sideways to formation of nanosheets on the surface of $\mathrm{ZnO}$ nanorods. Based on our results, it was speculated that ZnO NR-NS hierarchical nanostructures prepared by a two-step citrate assisted hydrothermal procedure could be applied to other substrates for building $\mathrm{ZnO}$ hierarchical nanostructures. 


\section{Conclusion}

In summary, a facile two-step hydrothermal process was developed to prepare $\mathrm{ZnO}$ NR-NS hierarchical nanostructures containing long $\mathrm{ZnO}$ nanorods backbones and thin $\mathrm{ZnO}$ nanosheet branches on the stainless steel mesh. Based on the XRD results, wurtzite hexagonal structured $\mathrm{ZnO}$ was obtained. It was clear that nanosheets were uniformly covered on the surface of $\mathrm{ZnO}$ nanorods, resulting in enhancement of internal surface area. Meanwhile, the mechanism of ZnO NR-NS hierarchical nanostructures on the stainless steel mesh was discussed. We expect that this useful and simple approach to prepare $\mathrm{ZnO}$ hierarchical nanostructure will offer many promising applications in the future.

\section{References}

1. B. O'regan, M. Grätzel, A low-cost, high-efficiency solar cell based on dye-sensitized colloidal $\mathrm{TiO}_{2}$ films, Nature 353 (1991) 737-740.

2. A. Yella, H.W. Lee, H.N. Tsao, C. Yi, A.K. Chandiran, M.K. Nazeeruddin, E.W. G. Diau, C. Y. Yeh, S.M. Zakeeruddin, M. Grätzel, Porphyrin-sensitized solar cells with cobalt (II/III)-based redox electrolyte exceed 12 percent efficiency, Science 334 (2011) 629-634.

3. M. Law, L. Greene, J. Johnson, R. Saykally, P. Yang, Nanowire dye-sensitized solar cells, Nat. Mater. 4 (2005) 455-459.

4. S. B. Zhu, W. Wei, X. N. Chen, M. Jiang, Z. W. Zhou, Hybrid structure of polyaniline/ZnO nanograss and its application in dye-sensitized solar cell with performance improvement, J. Solid State Chem. 190 (2012) 174-179.

5. A. Martinson, J. Elam, J. Hupp, M. Pellin, ZnO nanotube based dye-sensitized solar cells, Nano Lett. 7 (2007) 2183-2187.

6. L. Y. Lin, M. H. Yeh, C. P. Lee, C. Y. Chou, R. Vittal, K. C. Ho, Enhanced performance of a flexible dye-sensitized solar cell with a composite semiconductor film of $\mathrm{ZnO}$ nanorods and $\mathrm{ZnO}$ nanoparticles, Electrochim. Acta 62 (2012) 341-347.

7. H. W. Chen, C. Y. Lin, Y. H. Lai, J. G. Chen, C. C. Wang, C. W. Hu, C. Y. Hsu, R. Vittal, K. C. Ho, Electrophoretic deposition of $\mathrm{ZnO}$ film and its compression for a plastic based flexible dye-sensitized solar cell, J. Power Sources 196 (2011) 4859-4864.

8. H. Dai, Y. Zhou, Q. Liu, Z. D. Li, C. X. Bao, T. Yu, Z. G. Zhou, Controllable growth of dendritic $\mathrm{ZnO}$ nanowire arrays on a stainless steel mesh towards the fabrication of large area, flexible dye-sensitized solar cells. Nanoscale 4 (2012) 5454-5460.

9. H. Tada, M. Kubo, Y. Inubushic, $\mathrm{S}$. Itob, $\mathrm{N}=\mathrm{N}$ bond cleavage of azobenzene through $\mathrm{Pt} / \mathrm{TiO}_{2}$ photocatalytic reduction Chem. Commun. (2000) 977-978.

10. Z. Liu, X. Zhang, S. Nishimoto, M. Jin, D. A. Tryk, T. Murakami, A. Fujishima, Highly ordered $\mathrm{TiO}_{2}$ nanotube arrays with controllable length for photoelectrocatalytic degradation of phenol. J. Phys. Chem. C 112(2008) 253-259.

11. X. L. Xu, X. Duan, Z.G. Yi, Z.W. Zhou, X.M. Fan, Y. Wang, Photocatalytic production of superoxide ion in the aqueous suspensions of two kinds of $\mathrm{ZnO}$ under simulated solar light. Catal. Comm. 12 (2010) 169-172.

12. S. B. Zhu, X. N. Chen, F. B. Zuo, M. Jiang, Z. W. Zhou, D. Hui, Controllable synthesis of $\mathrm{ZnO}$ nanograss with different morphologies and enhanced performance in dye-sensitized solar cells, J. Solid State Chem. 197 (2013) 69-74.

13. S. B. Zhu, L. M. Shan, X. N. Chen, L. He, J. J. Chen, M. Jiang, X. L. Xie, Z. W. Zhou, 
Hierarchical $\mathrm{ZnO}$ architectures consisting of nanorod and nanosheet via a solution route for photovoltaic enhancement in dye-sensitized solar cells, RSC Adv. 3 (2013) 2910-2916.

14. S. B. Zhu, L. M. Shan, X. Tian, X. Y. Zheng, D. Sun, X. B. Liu, L. Wang, Z. W. Zhou, Hydrothermal synthesis of oriented $\mathrm{ZnO}$ nanorod-nanosheets hierarchical architecture on zinc foil as flexible photoanodes for dye-sensitized solar cells, Ceram. Int. 40 (2014) 11663-11670.

15. B. Weintraub, Z. Zhou, Y. Li, Y. Deng, Solution synthesis of one-dimensional ZnO nanomaterials and their applications. Nanoscale 2 (2010) 1573-1587.

16. J. A. Parkinson, H. Sun, New approach to the solution chemistry of bismuth citrate antiulcer complexes. Chem. Commun. (1998) 881-882. 